\title{
Oxygen consumption and evaporation during parturition in a vespertilionid bat (Pipistrellus pipistrellus)
}

\author{
P. I. Webb, J. R. Speakman and P. A. Racey \\ Department of Zoology, University of Aberdeen, Aberdeen AB9 2TN, UK
}

\begin{abstract}
Summary. Oxygen consumption and evaporation were measured in a single pregnant pipistrelle bat during labour and parturition of twins, using an open-flow respirometry system. During 233 min of measurements, three distinct phases were noted, which we suggest represent prelabour, labour and grooming or suckling the young.

On the basis of this hypothesis, during labour and parturition, oxygen consumption was a maximum of $8.9 \%$ of daily energy expenditure, evaporation was $2.7 \%$ of daily water turnover, and total water loss was $5.5 \%$ of daily water turnover in free-living bats in early lactation.

We estimated that, for the mother and young combined, oxygen consumption associated with grooming and suckling would be equivalent to $37.5 \%$ of daily energy expenditure of the mother, if carried out continuously. Similarly, evaporation due to grooming and suckling would be equivalent to $16.4 \%$ of daily water turnover.

In terms of daily energy expenditure and daily water turnover, labour and parturition are therefore cheap, but grooming and suckling (even ignoring costs in terms of losses in the milk) are expensive.
\end{abstract}

Keywords: bat; labour; parturition; oxygen consumption; evaporation

\section{Introduction}

During a comparative study on energetics and evaporation in pregnant and lactating pipistrelle bats, Pipistrellus pipistrellus, a heavily pregnant female gave birth to twins while oxygen consumption and evaporation were being monitored, providing a rare opportunity to examine how these two variables changed as the bat entered labour, gave birth, and then started to groom and suckle the young. These data enabled us to assess the impact of such processes on daily energy and water budgets.

\section{Materials and Methods}

A single bat was weighed to the nearest $0.01 \mathrm{~g}$ and placed in a respirometry chamber (volume $130 \mathrm{ml}$ ) containing a wooden trellis on which the bat could hang. The chamber was housed in an incubator (Gallenkamp type INL-401$010 \mathrm{~N}$ ) at an ambient temperature of $25^{\circ} \mathrm{C}$. The bat could be observed through a window in the door of the incubator. A layer of liquid paraffin in the bottom of the chamber trapped any urine and faeces produced. The chamber was connected into an open-flow respirometry system (Webb et al., in press) through which air was pumped at $93 \mathrm{ml} / \mathrm{min}$. Oxygen content of outflowing gas was measured using a single-channel paramagnetic oxygen analyser (1100 series, Servomex Ltd) and logged automatically on a microcomputer (BBC B series, Acorn Computers Ltd). Values of oxygen consumption $(\mathrm{ml} / \mathrm{min}=$ flow rate $\times[0.2095-$ oxygen content of outflowing gas $]$ ) were corrected to standard temperature and pressure and converted to energy expenditure (in watts) by taking a calorific value of oxygen of $20.1 \mathrm{~J} / \mathrm{ml}$ (using the equation of Elia \& Livesey, 1988, for a non-protein respiratory quotient of 0.8 ). Evaporation was calculated from the difference in relative humidity between the inflowing and the outflowing gas as measured using capacitive integer humidity probes (Väisälä). After $233 \mathrm{~min}$, the bats were removed and weighed. 


\section{Results}

The bat had an initial body mass of $9.95 \mathrm{~g}$ and a final mass (including the two young) of $9.53 \mathrm{~g}$. The behaviour of the bat was observed seven times during respirometry; on each observation the adult bat was sedentary, hanging with head downwards on the trellis. During the first 66 min (four observations), the bat was inactive, but during the last $158 \mathrm{~min}$ (three observations) it was seen grooming the ventral surface in the region of the genital opening and beneath the wings in the region of the nipples. The young were not visible during any of the observations. On removing the bats from the chamber, the young were noticed, attached one to each of the adult's nipples, tucked away out of sight under her wings. No faeces were produced by the bats during the experiment.
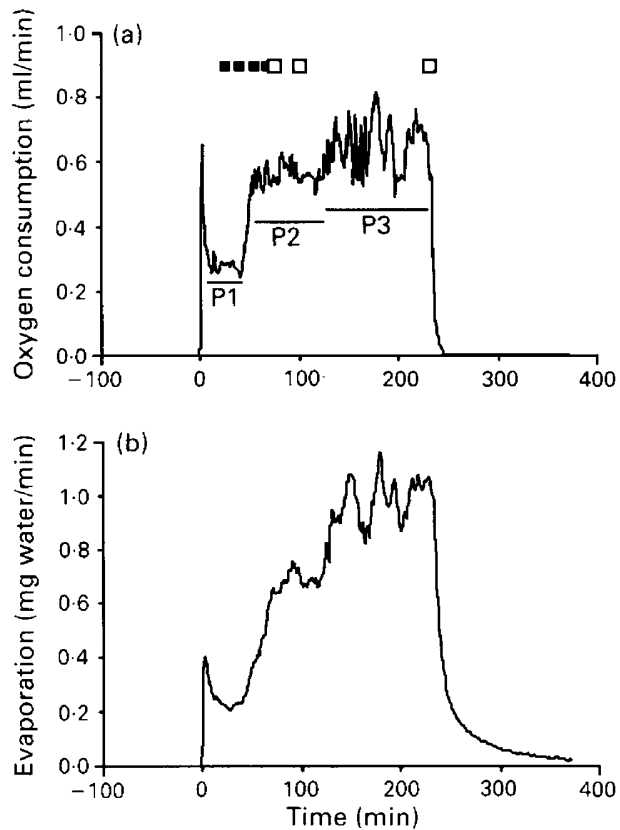

Fig. 1. Change in (a) oxygen consumption of and (b) evaporation from a pipistrelle bat placed in a chamber at $0 \mathrm{~min}$, and removed at $233 \mathrm{~min}$. In (a) three temporal phases are represented by P1, P2 and P3. Behaviour of the bat was observed seven times, when it was active ( $\square$ ) or inactive (ם).

After the bat was placed in the chamber, measured oxygen consumption rose rapidly and then settled to a stable rate within the following $8 \mathrm{~min}$ (Fig. Ia). Subsequently, there were three distinct phases in the rate of oxygen consumption (Table 1) (one-way ANOva on interphase variation in oxygen consumption, $F_{2.215}=603, P<0.001$ ). Total oxygen consumption during the experiment was $128.5 \mathrm{ml}$.

Continuous absorption and re-release of water vapour by the liquid paraffin resulted in a slow response in the relative humidity of the outflowing gas to changes in evaporation, but it was possible to identify plateaux in evaporation corresponding to the three phases of oxygen consumption (Fig. 1b, Table 1) (one-way ANOva on interphase variation, $F_{2,175}=1458, P<0.001$ ). The experimental design meant that there was inevitably a positive correlation between evaporation and relative humidity. As water pressure gradient is a primary determinant of evaporation, this correlation imposed a negative feedback when evaporation was high, thus reducing the significance of any differences in evaporation between the three phases. Total evaporation during the experiment was $0 \cdot 18 \mathrm{~g}$ water. 
Table 1. Oxygen consumption, evaporation and relative humidity of chamber in the three temporal phases between the start $(0 \mathrm{~min})$ and the end $(233 \mathrm{~min})$ of respirometry in a pipistrelle bat; the phases were shorter for evaporation and chamber relative humidity because of the lag time of the system

\begin{tabular}{|c|c|c|c|}
\hline & \multicolumn{3}{|c|}{ Phase } \\
\hline & 1 & 2 & 3 \\
\hline $\begin{array}{l}\text { Approximate time since } \\
\text { the start (min) }\end{array}$ & $8-43$ & $52-124$ & $125-233$ \\
\hline \multicolumn{4}{|c|}{ Oxygen consumption $(\mathrm{ml} / \mathrm{min})$} \\
\hline Duration (min) & 36 & 73 & 109 \\
\hline Mean \pm SD & $0.27 \pm 0.02$ & $0.56 \pm 0.03$ & $0.64 \pm 0.07$ \\
\hline Range & $0.23-0.32$ & $0.49-0.63$ & $0.48-0.82$ \\
\hline \multicolumn{4}{|c|}{ Evaporation (mg water/min) } \\
\hline Duration (min) & 21 & 53 & 104 \\
\hline Mean \pm SD & $0.22 \pm 0.01$ & $0.68 \pm 0.03$ & $0.98 \pm 0.08$ \\
\hline Range & $0 \cdot 20-0 \cdot 23$ & $0.63-0.75$ & $0 \cdot 82-1 \cdot 16$ \\
\hline \multicolumn{4}{|c|}{ Chamber relative humidity $(\%)$} \\
\hline Duration (min) & 21 & 53 & 104 \\
\hline Mean \pm SD & $45 \cdot 1 \pm 0 \cdot 4$ & $63 \cdot 7 \pm 1 \cdot 7$ & $77 \cdot 0 \pm 3 \cdot 6$ \\
\hline Range & $44.4-45 \cdot 6$ & $61 \cdot 2-67 \cdot 8$ & $69 \cdot 0 \div 85 \cdot 1$ \\
\hline
\end{tabular}

\section{Discussion}

During parturition, noctule bats (Nyctalus noctula) (Kleiman, 1969) and pipistrelle bats (P. A. Racey \& J. R. Speakman, unpublished data) assume a vertical position with head facing upwards, with delivery of the fetus in noctules taking $\approx 15-20$ minutes (Kleiman, 1969). The bat in the present study was never observed in this 'head up' position and the frequency of visual observations during the first two phases (Fig. la) suggests that parturition did not occur during this time. We suggest that phase 1 represents pre-labour, the bat entering labour either at the start of or in the middle of phase 2, and giving birth at the start of phase 3 , the high oxygen consumption and evaporation during phase 3 representing a combination of grooming and suckling behaviour by the mother, and oxygen consumption of and evaporation from the young.

Daily energy expenditure and water turnover in free-living pipistrelle bats during early lactation has been estimated at $28.5 \mathrm{~kJ} /$ day $(n=2$, SEM $=0 \cdot 10$, Racey \& Speakman, 1987) and $6.66 \mathrm{~g}$ water/day $(n=2$, SEM $=0 \cdot 20$, J. R. Speakman \& P. A. Racey, unpublished data) using doubly labelled water. Though the precise time at which parturition occurred in the present study is not known, it is clear that the whole process of labour and parturition took place within the $233 \mathrm{~min}$ of the experiment. Thus, together labour and parturition cannot have resulted in an additional expenditure of energy of $>2.58 \mathrm{~kJ}$ (equal to $8.9 \%$ of daily energy expenditure), additional evaporation of $>181.9 \mathrm{mg}(2.7 \%$ of daily water turnover), or an additional total water loss (evaporation plus fluids associated with parturition plus urine $=$ total mass loss $)$ of $>0.42 \mathrm{~g}(6.3 \%$ of daily water turnover). Assuming that resting costs of the adult were equal to those measured during phase 1 (Fig. la,b, Table 1), maximum additional costs resulting from labour and parturition would be $1.32 \mathrm{~kJ}(4.6 \%$ of daily energy expenditure), $130.6 \mathrm{mg}$ evaporation $(2.0 \%$ of daily water turnover) and $0.37 \mathrm{~g}$ total water loss (5.6\% of daily water turnover).

If the mean costs measured in phase 3 (Fig. la,b, Table 1) represent the costs of grooming and suckling the young (including oxygen consumption of and evaporation from the young themselves), grooming and suckling would represent additional costs of $0.12 \mathrm{~W}(10.7 \mathrm{~kJ} /$ day, $37.5 \%$ of daily energy expenditure, if continuous for $24 \mathrm{~h}$ ) and $0.76 \mathrm{mg} / \mathrm{min}$ evaporation $(1.09 \mathrm{~g} /$ day, $16 \cdot 4 \%$ of daily water turnover, if continuous for $24 \mathrm{~h})$. 
We therefore suggest that, in terms of daily energy expenditure and daily water turnover, labour and parturition are cheap, especially as they only occur once a year, while grooming and suckling (even ignoring costs in terms of losses in the milk) are more expensive.

This work was supported by a postgraduate studentship from the Natural Environment Research Council. We thank J. P. Hayes for critical comments on an earlier draft of the manuscript, and S. Frears and A. Burnett for help in animal care.

\section{References}

Elia, M. \& Livesey, G. (1988) Theory and validity of indirect calorimetry during net lipid synthesis. American Journal of Clinical Nutrition 47, 591-607.

Kleiman, D.G. (1969) Maternal care, growth rate, and development in the noctule (Nyctalus noctula), pipistrelle (Pipistrellus pipistrellus), and serotine (Eptesicus serotinus) bats. Journal of Zoology 157, 187-211.

Racey, P.A. \& Speakman, J.R. (1987) The energy costs of pregnancy and lactation in heterothermic bats.
Symposium of the Zoological Society of London 57, 107-126.

Webb, P.I., Hays, G.C., Speakman, J.R. \& Racey, P.A. The functional significance of ventilation frequency, and its relationship to oxygen demand in the resting brown long-eared bat, Plecotus auritus. Journal of Comparative Physiology, B. (in press).

Received 12 August 1991 